\title{
Numerical simulations of sand production in oil wells using the CFD-DEM-IBM approach
}

\author{
Aigerim K. Rakhimzhanova ${ }^{\mathrm{a}, *}$, Colin Thornton $^{\mathrm{b}}$, Yerlan Amanbek ${ }^{\mathrm{a}}$ \&Yong Zhao ${ }^{\mathrm{a}}$ \\ ${ }^{a}$ Nazarbayev University, Astana 010000, Kazakhstan \\ ${ }^{b}$ University of Birmingham, Edgbaston, Birmingham B15 2TT, UK
}

\begin{abstract}
Three-dimensional CFD-DEM-IBM simulations of sand production in a sandstone formation, using periodic boundaries, were performed using 10000 frictional elastic spheres bonded together and compressed at $1 \mathrm{MPa}$ of overburden pressure. Sand production simulation geometry and procedure are proposed, in which the cone penetration test (CPT) has been used to investigate a physical perforation penetration of the cemented sandstone material with the realworld grain size distribution from the Ustyurt-Buzachi Sedimentary Basin. The Immersed Boundary Method (IBM) was adapted for the sand production simulation geometry to simulate the fluid flow near the well casing. Oil with low viscosity and density was used as an injection fluid (reservoir fluid). Erosion near the perforation tunnel due to the pressure drawdown was examined, where the production of sand particles was initiated during the first flow due to the drag force that lifted the sand particles from the perforation damage zone. At the beginning of the simulation a sand arch was captured around the perforation tunnel and due to the fluid flow it collapsed and perforation cavity became larger. The amount and mass of produced sand particles were calculated.
\end{abstract}

Keywords: DEM; CFD, IBM, sand production, cone penetration test, cemented sand, sandstone reservoir

\section{INTRODUCTION}

The modelling of amount of sand production is still one of major issues in the oil and gas production. This problem is particular prominent in terrigenous/sandstone reservoirs, which is common to observe in majority of the oil and gas reservoir fields. Typical substances of the sandstone reservoir are quarts, mica, rock fragments and different type of mineral grains with silica, cements or clay (Bjorlykke, 2010). In addition, such reservoir has a high porosity (0.15) and permeability (from 25 to 100 Darcies). When sand particles start to erode from weak sandstone formations for different reasons, the impact could lead to degradation of the equipment and deterioration of the production flow rate. The filling of the well with sand can cease the flow and result in collapse of the casing. The damage to the surface equipment by erosion or plugging can increase the cost of production. In addition, the management of the eroded sand is vital to prevent the negative impact to the environment (Carlson et al., 1992). This wide range phenomenon depends on various factors. Veeken et al. (1991) classified parameters and factors influencing sand production into the three categories: formation, completion and production. The formation category is mostly associated with rock and reservoir properties, like strength, permeability and pressure distribution; the type and technique of well completion, such as 
wellbore orientation, perforation, etc. lie within the completion category; and the production category includes flow rate, drawdown pressure and depletion of the reservoir pressure.

Based on these parameters, the types of sand production (transient, continuous and catastrophic) and sanding mechanisms (shear and tensile failures, erosion and transportation of fine particles) will differentiate. Experimental and numerical models of sand production problem are the key approaches in finding a solution for the sand production problem, at the same time with increasing computing power the numerical modelling becomes one of the powerful tools for predicting sand production (Rahmati et al., 2013). This can be developed by incorporating the physics of fluid and solid interactions at the micro scale to improve modelling of the detachment of particles from the intact sandstone and their transport with the fluid flow. It requires the coupled modelling technique of Discrete-Element-Method (DEM) and Computational-FluidDynamics (CFD). Cundall and Strack (1979) introduced the Discrete Element Method (DEM) which is a powerful tool to model sanding mechanism, where each sand particle is considered as an individual entity. This method can simulate disaggregation of particles from the rock matrix, i.e. degradation and dissemination rock due to the erosion to small sand particles. Using this discontinues approach we can calculate the mass and volume of produced sand and study its mechanism.

In the last twenty years, several researchers numerically studied the sand production phenomena using the CFD-DEM approach since it was first introduced by Tsuji et al. (1993). O'Connor et al. (1997) and Jensen and Preece (2000) were implemented the 2D continuity equation and Darcy's law using the FEM into the 2D DEM code (MIMES) developed at the Massachusetts Institute of Technology and introduced the application of 2D CFD-DEM modelling to simulate the sanding problem in oil recovery, in particular to investigate the role of flow rate in the matrix collapse and the magnitude of bond strength, respectively. O'Connor et al. (1997) used irregular particle shapes as sand grains and Jensen and Preece (2000) used n-sided polygon shapes; and in both studies the particles were bonded together by cohesive strength (to represent cementation of sand particles), where only the tensile bond failure mode was considered. Jensen and Preece (2000) reported that as the bonds cohesion decreased, the number of particles breaking free from the matrix increased.

Li and Holt (2002) implemented the 2D Darcy's Law into the 2D DEM code (PFC2D), where fluid flow networks and simulating flow along the flow paths connecting the voids through the pipes. Further, Li et al. (2006) have modelled the hollow cylinder tests with fluid flow to study the sanding mechanism, where the 2D Darcy's law using the FEM with a superimposed mesh implemented to the 2D code (PFC2D). Circular disks (scaled-up) were used as a particle shape and inserted bonds between them, where bonds are a simple beam and have normal and shear stiffness and strength. In their simulations, Li et al. (2006) obtained three typical failure patterns, which is analogous to those observed in laboratory experiments. In case, if the material is prone to localized compressive failure due to grain crushing, the observed failure pattern is a slit-like breakout. The uniform failure of material around the borehole was observed, when the tensile strength was low and the material was weak. In the last case, if the material is relatively strong and does not form shear bands, the observed failure pattern is that of dog-eared breakouts.

All the coupling techniques mentioned above used Darcy's Law for the sand production simulation. The Darcy fluid flow is not the best description of the physics where particles are being transported by the fluid, it is insufficient to represent real 3D fluid flow effect during the oil recovery process and it is valid for slow and viscous flow. O'Connor et al. (1997) and Jensen 
and Preece (2001) suggested using a much larger number of particles to avoid the influence of boundary effects. The need to model the problem using 3D CFD-DEM (Rahmati et al., 2013) is conditioned by the three-dimensional complex geometry pore flow networks and intergranular.

Cheung (2010) implemented the simplified 1-D fluid scheme calculating solely the continuity equation into the PFC3D to simulate the impact of fluid flow on sand production. The scaled-up DEM particles generated in a block sample, where particles then bonded by parallel bond and compressed for the perforation simulations, the cylindrical specimen was cut from this block sample and the inner cylindrical wall was simply deleted to mimic the perforation hole. After, this specimen was overlain by fluid cells in cylindrical coordinate, where the fluid flow assumed to flow radially from the outer cylinder to inner perforation hole. This simplified 1-D fluid scheme was unable to simulate the full effect of fluid flow as circumferential and vertical flow were considered to be significant, where the drag force was applied in one direction. Only the effect of the fluid flow on the particles was considered, but not the effect of the particles on the fluid flow. Also, the radial flow is not representative at the perforation tip, where the flow is in multidirectional.

Zhou et al. (2011) coupled 3D CFD based on the Navier-Stokes equations into the 3D DEM code (PFC3D) to simulate the sand erosion by fluid flow in a weakly bonded sand assembly. A portion of cylindrical domain was used as geometry, where spherical particles (without upscaling) bonded together, and linear-elastic law was used to calculate the contact forces between particles. They simply removed the inner cylindrical wall, which mimic a perforation hole. Authors concluded that the fluid flow rate and bonding properties are significantly affects to sand erosion, erosion rate increased when the sand strength decreased and fluid rate increased. They simulated the simplified conditions and concluded the positive applicability of microscale modelling to study sand erosion. In order to represent laboratory and field conditions better, model boundary conditions were suggested to be used by the authors.

Climent (2016) coupled 3D DEM with 3D CFD based on the Navier-Stokes equations (PFC3D). Author used sandstone analogue prepared by Cheung (2010) and tested it under different fluid flow conditions. She reported that with increasing the fluid flow velocity, the plastic region and sand production rate were also increase. However, this model constrained to consider influence of gradient of pressure on particles and was not able to represent the fluid pressure on each particle.

Cui et al. (2016) developed particle-fluid model (PFC3D) using the Darcy's Law equations and proposed a new methodology for grid block permeability and porosity distribution at in response both to deformation and sanding, also they used a new approach to sand grains seepage forces calculation on. Scaled-up spherical particles (bonded by parallel bonds) were generated in a rectangular DEM box, which was then overlain with fluid cells in cylindrical coordinate system. For the imitation of perforation hole, the cylindrical borehole was created by a slow grain stiffness reduction inside the borehole to zero and grains inside the borehole were removed. This block-shaped sample was tested under different pressure conditions and far-field stresses. Authors concluded that the size and failure mode is affected by fluid flow the breakout zone and sand production as well as the boundary stress. The less sanding was observed at boundary fluid pressure despite higher boundary stress, whereas strong frictional interlocking caused by high tangential stresses around the borehole caused by high confining stress resulted in moderate sand production. A large amount of sand was produced at high flow rates despite lower far-field stress. 
All the coupling techniques using 3D DEM-fluid models and sand production simulations mentioned above were performed in PFC3D. All authors, except Zhou et al. (2011) used scaledup DEM particles and bonded these particles by parallel bonds, and simplifies perforation technique and they suggested to conduct physical perforation tests; to use periodic boundaries to make calibration process more efficient, to use the DEM particles similar to the real grain sizes for the future work. Climent (2016) concluded that the parallel bond model calibration was still simplistic and a development of the better calibration with more macro parameters was needed and upscaling of model in capturing behaviour of fine scale system was desirable to extend knowledge of the fluid-particle interaction in the multiscale system.

This preprint paper presents the sample preparation procedure/method with physical perforation penetration and sand production modelling in periodic cell using the 3D CFD-DEM modelling and complex boundaries using the Immersed Boundary Method (IBM), and all the suggestions made by the above mentioned researchers were taking into account. As the preliminary results, one simulation test case has been presented to show the capability of this method to capture the damage zone (skin) due to the perforation penetration and the sanding mechanism (erosion near the perforation hole) due to the fluid flow.

\section{NUMERICAL METHODS AND GOVERNING EQUATIONS}

Kafui et al. (2002) developed DEM fluidised bed simulation code at Birmingham University by coupling the DEM code provided by Cundall and Strack (1979) and the CFD code based on 2D and 3D Navier-Stokes solvers for compressible flows provided by Kuipers et al. (1993). Further, Guo et al. (2012) incorporated the IBM method into this CFD-DEM approach to model gas and particle two-phase flows with complex and moving boundaries.

In this study, the 3D CFD-DEM-IBM code was used, where the IBM part was adapted for the geometry of sand production modelling. All the DEM sand particles are considered to be elastic and frictional, where the particle-LSO (Large-Sized Objects) and particle-particle contact forces without adhesion are calculated using the theories of Hertz (1881) to determine the normal force, and Mindlin (1949) to calculate the tangential force. A simple 3D bond contact model for cemented sandstone material developed by Rakhimzhanova et al. (2018, 2019a) was used to calculate the interparticle normal contact force with adhesion, where authors simply modified the previous existing JKR model for auto-adhesive silt sized particles provided by Johnson et al. (1971) and Johnson (1976). Further, the 2D and 3D Navier-Stokes solvers for compressible flow were modified to an incompressible flow solver since the CFD-DEM modelling of sand production is not a large-scale simulation that can capture the density changes caused by pressure or temperature changes as in real field conditions. The flow can be approximated as incompressible if flow-induced pressure changes do not cause significant density changes.

\subsection{FLUID-PARTICLE INTERACTION FORCE}

We consider the single-phase fluid and large numbers of fine solid particles form numerical

modelling. The total force $F_{i}$ acting on particle $i$ incorporated into the CFD-DEM-IBM approach has several components: $f_{c i}$ is the sum of the solid particle-particle contact force and the particle- 
LSO contact force, $\mathrm{f}_{\mathrm{fpi}}$ is the fluid-particle interaction force, a gravitational force $m_{\mathrm{i}} g$. The translational and rotational motions of each particle are governed by Newton's second law:

$$
\begin{aligned}
& m_{\mathrm{i}} \frac{d v_{\mathrm{i}}}{d t}=\mathrm{F}_{\mathrm{i}}=\mathrm{f}_{\mathrm{ci}}+\mathrm{f}_{\mathrm{fpi}}+\mathrm{m}_{\mathrm{i}} \mathrm{g} \\
& I_{\mathrm{i}} \frac{d \omega_{\mathrm{i}}}{d t}=\mathrm{T}_{\mathrm{i}}
\end{aligned}
$$

where $I_{\mathrm{i}}, v_{\mathrm{i}}$ are the momentum inertia, angular and linear velocities of the particle $i$, respectively; and $T_{i}$ is the torque arising from the tangential components of the contact force. Following Anderson and Jackson (1967), the fluid-particle interaction force, $\mathrm{f}_{\mathrm{fpi}}$, can be expressed as:

$$
\mathrm{f}_{\mathrm{fpi}}=-v_{\mathrm{pi}} \nabla p+v_{\mathrm{pi}} \nabla \cdot \tau_{\mathrm{f}}+\varepsilon \mathrm{f}_{\mathrm{di}}
$$

where $v_{\mathrm{pi}}$ is the volume of particles, $p$ is the local fluid pressure, $\varepsilon$ is the local void fraction, $\mathrm{f}_{\mathrm{di}}$ is the drag force, $\tau_{\mathrm{f}}$ is the local viscous stress tensor.

Di Felice's (1994) proposed an empirical correlation to calculate the drag force $\mathrm{f}_{\mathrm{di}}$ on particle $i$

$$
f_{d i}=\frac{1}{2} C_{D i} \rho_{f j} \frac{\pi d_{p i}^{2}}{4} \varepsilon_{j}^{2}\left|u_{f j}-v_{i}\right|\left(u_{f j}-v_{i} \chi\right) \varepsilon^{-\chi}
$$

where $\rho_{\mathrm{fj}}, \mathrm{u}_{\mathrm{fj}}$ and $\varepsilon_{\mathrm{j}}$ are the fluid density, fluid velocity and void fraction of the fluid cell $j$, where particle $i$ of diameter $d_{\mathrm{pi}}$ resides; $\varepsilon^{-\chi}$ is a correction for the presence of other particles and the correlation equation for $\chi$ obtained by Di Felice (1994) which takes account of the variation of this exponent in the intermediate flow regime as well as the near constant values in the low and high Reynolds number flow regimes:

$$
\chi=3.7-.065 \exp \left[-\frac{\left(1.5-\log _{10} R e_{p i}\right)^{2}}{2}\right]
$$

$C_{\mathrm{Di}}$ is the fluid drag coefficient for a single unhindered particle:

$$
C_{\mathrm{Di}}=\left[0.63+\frac{4.8}{\sqrt{\mathrm{Re}_{\mathrm{pi}}}}\right]^{2}
$$

The particle Reynolds number $R e_{p i}$, which is based on the superficial slip velocity between fluid and particle, is

$$
\operatorname{Re}_{\mathrm{pi}}=\frac{\rho_{\mathrm{f}} d_{\mathrm{pi}} \varepsilon_{\mathrm{j}}|\mathrm{u}-\mathrm{v}|}{\mu_{\mathrm{s}}}
$$

We expect that the viscous stress tensor depends only on the fluid motion (Bird et al., 1960)

$$
\tau_{\mathrm{f}}=\left[\left(\mu_{\mathrm{b}}-\frac{2}{3} \mu_{\mathrm{s}}\right) \nabla \cdot \mathrm{u}_{\mathrm{f}}\right] \delta+\mu_{\mathrm{s}}\left[\left(\nabla \mathrm{u}_{\mathrm{f}}\right)+\left(\nabla \mathrm{u}_{\mathrm{f}}\right)^{\mathrm{T}}\right]
$$

where $\mu_{\mathrm{b}}$ and $\mu_{\mathrm{s}}$ are the bulk and shear viscosities, $\mathrm{u}_{\mathrm{f}}$ is velocity of the fluid, respectively. 
In this study, the incompressible flow was considered; therefore the fluid $\rho_{\mathrm{f}}$ is always a constant value.

\subsection{PARTICLE-FLUID INTERACTION FORCE}

The continuity and momentum equations for the hydrodynamics of incompressible fluid in a granular system are

$$
\begin{aligned}
& \frac{d\left(\rho_{\mathrm{f}} \varepsilon\right)}{d t}+\nabla \cdot \rho_{\mathrm{f}}\left(\varepsilon \mathrm{u}_{\mathrm{f}}\right)=0 \\
& \frac{d\left(\rho_{\mathrm{f}} \varepsilon \mathrm{u}_{\mathrm{f}}\right)}{d t}+\nabla \cdot \rho_{\mathrm{f}}\left(\varepsilon_{e} \mathrm{u}_{\mathrm{f}} \mathrm{u}_{\mathrm{f}}\right)=-\nabla p+\nabla \cdot \tau_{\mathrm{f}}-\mathrm{F}_{\mathrm{fp}}+\varepsilon \rho_{\mathrm{f}} \mathrm{g}
\end{aligned}
$$

where $F_{f p}$ is the fluid-particle interaction force per unit bed volume and it is obtained as

$$
\mathrm{F}_{\mathrm{fp}}=\frac{1}{V_{\text {cell }}} \sum_{i=1}^{n_{\mathrm{c}}} \mathrm{f}_{\mathrm{fpi}}=-(1-\varepsilon) \nabla p+(1-\varepsilon) \nabla \cdot \tau_{\mathrm{f}}+\frac{1}{V_{\text {cell }}} \sum_{i=1}^{n_{\mathrm{c}}} \varepsilon \mathrm{f}_{\mathrm{fpi}}
$$

where $n_{c}$ is the number of particles in a fluid cell of volume $V_{\text {cell }}$. The momentum equation can be expressed by substituting Eq.11 into Eq.10.

$$
\frac{d\left(\rho_{\mathrm{f}} \varepsilon \mathrm{u}_{\mathrm{f}}\right)}{d t}+\nabla \cdot\left(\rho_{\mathrm{f}} \varepsilon_{e} \mathrm{u}_{\mathrm{f}} \mathrm{u}_{\mathrm{f}}\right)=-\varepsilon \nabla p+\varepsilon \nabla \cdot \tau_{\mathrm{f}}-\mathrm{F}_{\mathrm{fp}}^{*}+\varepsilon \rho_{\mathrm{f}} \mathrm{g}
$$

where $\mathrm{F}_{\mathrm{fp}}^{*}$ expressed as

$$
\mathrm{F}_{\mathrm{fp}}^{*}=\frac{1}{V_{\text {cell }}} \sum_{i=1}^{n_{\mathrm{c}}} \varepsilon \mathrm{f}_{\mathrm{fpi}}
$$

\subsection{PARTICLE-FLUID INTERACTION WITH THE IMMERSED BOUNDARY METHOD}

Peskin (1972) introduced the Immersed Boundary Method (IBM) to simulate arbitrarily complex geometries with sophisticated and mobile boundaries, which do not conform to the CFD-DEM Eulerian rectangular grids. Guo et al. (2013) incorporated the IBM method into an existing CFD-DEM code to model gas-particle two-phase flows with complex and moving boundaries based on the previous IBM development for modelling of particulate systems consisting of gas and solid particles proposed by Kajishima et al. (2001). This method is used when the multiphase system involves a fluid, many fine solid particles and one or more LSOs and it deals with the interaction between fluid flow and LSO.

The volume of a single fluid cell $V_{\text {cell }}$, can be expressed as the sum of the volume of the fine particles, $V_{\mathrm{p}}$, th volume of the LSO, $V_{\mathrm{obj}}$, and the volume of the fluid in this cell, $V_{\mathrm{f}}$

$$
V_{\text {cell }}=V_{\mathrm{p}}+V_{\mathrm{obj}}+V_{\mathrm{f}}
$$

The volume fraction of the fluid cell excluding the fine particles is defined as the effective void fraction: 


$$
\varepsilon_{e}=1-\frac{V_{\mathrm{p}}}{V_{\text {cell }}}=\frac{V_{\mathrm{obj}}+V_{\mathrm{f}}}{V_{\text {cell }}}
$$

and the volume fraction of the LSO in a fluid cell is defined as

$$
\alpha=\frac{V_{\text {obj }}}{V_{\text {cell }}}
$$

Yuki et al (2007) proposed a simple algorithm to evaluate the value of $\alpha$ at the collocation point for each cell

$$
\begin{aligned}
& \alpha=0.5\left[1-\tanh \left(\frac{\Delta}{\sigma \lambda d_{\text {cell }}}\right)\right] \\
& \lambda=\left|n_{x}\right|+\left|n_{y}\right|+\left|n_{z}\right| \\
& \sigma=0.05\left(1-\lambda^{2}\right)+0.3
\end{aligned}
$$

where $d_{\text {cell }}$ is the cell size, $n=\left(n_{x}, n_{y}, n_{z}\right)$ is a normal outward unit vector at a surface element and $\sigma$ is a signed distance from the cell centre to the surface element.

Kajishima et al. (2001) established a unified velocity, $u$, to describe the fluid-LSO system by volume averaging the local fluid velocity, $\mathrm{u}_{\mathrm{f}}$, and the local solid object velocity, $\mathrm{U}_{\mathrm{obj}}$, for each fluid cell:

$$
\mathrm{u}=\frac{V_{\mathrm{f}}}{V_{\mathrm{obj}}+V_{\mathrm{f}}} \mathrm{u}_{\mathrm{f}}+\frac{V_{\mathrm{obj}}}{V_{\mathrm{obj}}+V_{\mathrm{f}}} \mathrm{U}_{\mathrm{obj}}=\frac{\varepsilon_{e}-\alpha}{\varepsilon_{e}} \mathrm{u}_{\mathrm{f}}+\frac{\alpha}{\varepsilon_{e}} \mathrm{U}_{\mathrm{obj}}
$$

where the local LSO velocity, $\mathrm{U}_{\mathrm{obj}}$, is computed by taking average of the local velocities at solid points over the volume of the LSO falling in a fluid cell, $V_{\mathrm{obj}}$ :

$$
\mathrm{U}_{\mathrm{obj}}=\frac{1}{V_{\mathrm{obj}}} \int_{V_{\mathrm{obj}}}\left(\mathrm{v}_{\mathrm{LSO}}+\omega_{\mathrm{LSO}}+r\right) d V=\mathrm{v}_{\mathrm{LSO}}+\frac{1}{V_{\mathrm{obj}}} \int_{V_{\mathrm{obj}}} \omega_{\mathrm{LSO}}+r d V
$$

in which, $\mathrm{v}_{\mathrm{LSO}}$ and $\omega_{\mathrm{LSO}}$ are the translational and rotational velocities of the LSO and $r$ is the relative position from the centre of mass of the object to a local point on the object.

The continuity and momentum equations for the hydrodynamics of incompressible fluid in a granular system and in presence of the LSO are (based on the governed equations for compressible flow by Guo et al., 2012)

$$
\begin{gathered}
\frac{d\left(\varepsilon_{e}\right)}{d t}+\nabla \cdot\left(\varepsilon_{e} \mathrm{u}\right)=0 \\
\rho_{\mathrm{f}} \frac{d\left(\varepsilon_{e} \mathrm{u}\right)}{d t}+\rho_{\mathrm{f}} \nabla \cdot\left(\varepsilon_{e} \mathrm{uu}\right)=-\varepsilon_{e} \nabla p+\varepsilon_{e} \nabla \cdot \tau-\mathrm{F}_{\mathrm{fp}}^{*}+\rho_{\mathrm{f}} \varepsilon_{e} \mathrm{~g}+\mathrm{f}^{\prime}
\end{gathered}
$$

where, the fluid-LSO is treated as a single continuum with a unified velocity field, $\mathrm{u}$, because the no-slip and impermeable conditions at fluid-solid interface with $\mathrm{u}_{\mathrm{f}}=\mathrm{U}_{\mathrm{obj}}$ was considered; and the term $\mathrm{f}^{\prime}$ is the virtual body force used to correct the velocity field, $\mathrm{u}$, at the fluid-solid interface and inside the LSO. Subsequently, the viscous stress tensor $\tau$ is given by Eq.4 is used 
with $\mathrm{u}$ replacing $\mathrm{u}_{\mathrm{f}}$; the effective void fraction, $\varepsilon_{e}$, is used in both governing equations to take into account the effect of the presence of fine particles. However, the real void fraction is used in the Eqs. 5 and 11 to calculate the drag force $\mathrm{f}_{\mathrm{di}}$ and the fluid-particle interaction force $\mathrm{F}_{\mathrm{fp}}^{*}$, respectively and obtained from

$$
\varepsilon=1-\frac{V_{\mathrm{p}}}{V_{\mathrm{cell}}-V_{\mathrm{obj}}}=\frac{\varepsilon_{e}-\alpha}{1-\alpha}
$$

The momentum Eq.22 is discretised in time using the first-order finite difference algorithm:

$$
\rho_{f}\left(\varepsilon_{e} u\right)^{n+1}=\rho_{f}\left(\varepsilon_{e} u\right)^{n}+\Delta t \cdot \mathrm{H}^{n}-\Delta t \cdot\left(\varepsilon_{e} \nabla p\right)^{n+1}+\Delta t \cdot\left(\mathrm{f}^{\prime}\right)^{n+1}
$$

where

$$
\mathrm{H}=-\nabla \cdot \rho_{\mathrm{f}}\left(\varepsilon_{e} \mathrm{uu}\right)+\varepsilon_{e} \nabla \cdot \tau_{\mathrm{f}}-\mathrm{F}_{\mathrm{fp}}^{*}+\rho_{\mathrm{f}} \varepsilon_{e} \mathrm{~g}
$$

and $\Delta t$ is the time step and superscripts implies the number of the time step.

Based on the location of the LSO, the main three variables $\alpha$, $\mathrm{u}$ and $\mathrm{f}^{\prime}$ of computational cells will be different:

1. For the computational cells outside the LSO, $\alpha=0, \mathrm{u}=\mathrm{u}_{\mathrm{f}}$ and there is no virtual force $\left(\mathrm{f}^{\prime}\right)^{n+1}=0$, therefore the momentum Eq. 22 reduces to Eq. 12 .

2. For the computational cells inside the LSO, the momentum Eq. 22 is used with $\alpha=1$, $u^{n+1}=\mathrm{U}_{\mathrm{obj}}{ }^{n+1}$ and the virtual body force, $\left(\mathrm{f}^{\prime}\right)^{n+1}$, can be derived from Eq. 24:

$$
\left(\mathrm{f}^{\prime}\right)^{n+1}=\frac{\rho_{f}\left(\varepsilon_{e} \mathrm{U}_{\mathrm{obj}}\right)^{n+1}-\rho_{f}\left(\varepsilon_{e} u\right)^{n}}{\Delta t}-\mathrm{H}^{n}+\left(\varepsilon_{e} \nabla p\right)^{n+1}
$$

3. For the computational cells at the fluid-solid interface that are partially occupied by the LSO, the momentum Eq. 22 is used with $0<\alpha<1, u^{n+1}=\mathrm{U}_{\mathrm{obj}}{ }^{n+1}$ and the virtual body force, $\left(\mathrm{f}^{\prime}\right)^{n+1}$, can be defined by a first-order linear interpolation using $\alpha$ defined in Eqs. 16-18.

$$
\left(\mathrm{f}^{\prime}\right)^{n+1}=\alpha\left[\frac{\rho_{f}\left(\varepsilon_{e} \mathrm{U}_{\mathrm{obj}}\right)^{n+1}-\rho_{f}\left(\varepsilon_{e} u\right)^{n}}{\Delta t}-\mathrm{H}^{n}+\left(\varepsilon_{e} \nabla p\right)^{n+1}\right]
$$

\section{Numerical Algorithm}

For the convenience of the reader we reiterate the previous algorithm (Guo et al., 2012) with modifications for incompressible flow case.

1. Compute the new velocities and new positions from Eqns. 1 and 2.

2. Compute the new velocity and new position of LSO.

3. For each cell compute $\varepsilon_{e}, \alpha$ and $\varepsilon$. 
4. Compute the virtual body force

5. Based on the pressure-correction method we compute $p^{\prime}$. First, $u^{n+1}$ is computed from the continuity system (Eq. 28). Second, $u^{*}$ is computed in Eq. 32 with provided $p^{*}$. Next, from Eqns. 33 we obtain $p^{\prime}$.

6. The piecewise constant in cell pressure at $(\mathrm{n}+1)^{\text {th }}$ time step can be found using $p^{n+1}=p^{*}+$ $p^{\prime}$.

7. Update $\left(\mathrm{f}^{\prime}\right)^{n+1}$ and $u^{n+1}$ using $p^{n+1}$.

8. Testing the convergence of continuity problem. If not, we repeat procedure from step 4 with $p^{*}:=p^{n+1}$. This iteration continues until the convergence criterion is satisfied.

9. From Eq. 19 we estimate $u_{f}^{n+1}$.

\subsection{PRESSURE-CORRECTION EQUATIONS}

A semi-implicit finite difference numerical technique employing a staggered grid is used in solving the incompressible Navier-Stokes equations on an equidistant 3D Cartesian grid. The adapted version of SIMPLE methodology (Semi-Implicit Method for Pressure-Linked Equations) proposed by Patanker (1980) is used as the algorithm. The pressures are defined at the center of each fluid cell, and the fluid velocity components are defined at the cell faces (Figure 1).

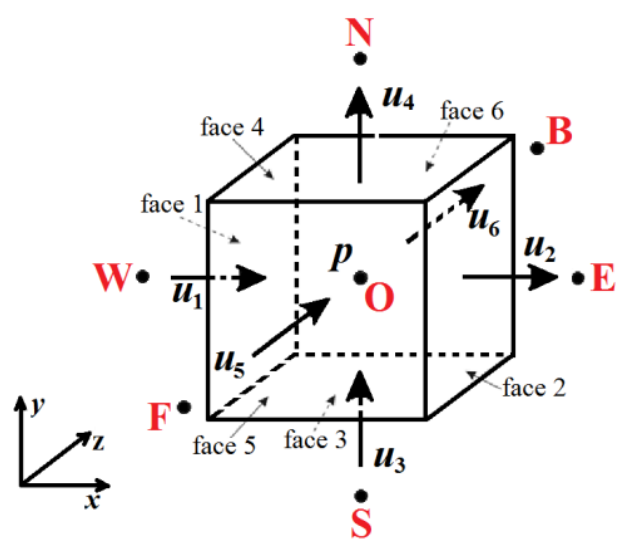

Figure 1. 3D control volume (cell)

For the cell center $\mathrm{O}$, the continuity equation (21) discretized as

$$
\begin{aligned}
\left(\varepsilon_{e}\right)_{0}^{n+1} & -\left(\varepsilon_{e}\right)_{0}^{n}+\frac{\Delta t}{\Delta x}\left[\left(\varepsilon_{e} u\right)_{2}^{n+1}-\left(\varepsilon_{e} u\right)_{1}^{n+1}\right]+\frac{\Delta t}{\Delta y}\left[\left(\varepsilon_{e} u\right)_{4}^{n+1}-\left(\varepsilon_{e} u\right)_{3}^{n+1}\right] \\
+ & \frac{\Delta t}{\Delta z}\left[\left(\varepsilon_{e} u\right)_{6}^{n+1}-\left(\varepsilon_{e} u\right)_{5}^{n+1}\right]=0
\end{aligned}
$$

The discretized momentum equation with virtual force 


$$
\rho_{f}\left(\varepsilon_{e} u\right)^{n+1}=(1-\alpha) \rho_{f}\left(\varepsilon_{e} u\right)^{n}+(1-\alpha) \Delta t H^{n}-(1-\alpha) \Delta t\left(\varepsilon_{e} \nabla p\right)^{n+1}+\alpha \rho_{f}\left(\varepsilon_{e} U_{o b j}\right)^{n+1}
$$

The momentum equation at $n+1$ at $1-6$ faces:

$$
\begin{aligned}
\rho_{f}\left(\varepsilon_{e} u\right)_{1}^{n+1}= & \left(1-\alpha_{1}\right) \rho_{f}\left(\varepsilon_{e} u\right)_{1}^{n}+\left(1-\alpha_{1}\right) \Delta t\left(H_{x}\right)_{1}^{n}-\left(1-\alpha_{1}\right) \frac{\Delta t}{\Delta x}\left(\varepsilon_{e}\right)_{1}^{n+1}\left(P_{O}^{n+1}-P_{w}^{n+1}\right)+ \\
& \alpha \rho_{f}\left(\varepsilon_{e} U_{o b j}^{x}\right)_{1}^{n+1} \\
\rho_{f}\left(\varepsilon_{e} u\right)_{2}^{n+1}= & \left(1-\alpha_{2}\right) \rho_{f}\left(\varepsilon_{e} u\right)_{2}^{n}+\left(1-\alpha_{2}\right) \Delta t\left(H_{x}\right)_{2}^{n}-\left(1-\alpha_{2}\right) \frac{\Delta t}{\Delta x}\left(\varepsilon_{e}\right)_{2}^{n+1}\left(P_{E}^{n+1}-P_{O}^{n+1}\right)+ \\
& \alpha \rho_{f}\left(\varepsilon_{e} U_{o b j}^{x}\right)_{2}^{n+1} \\
\rho_{f}\left(\varepsilon_{e} u\right)_{3}^{n+1}= & \left(1-\alpha_{3}\right) \rho_{f}\left(\varepsilon_{e} u\right)_{3}^{n}+\left(1-\alpha_{3}\right) \Delta t\left(H_{y}\right)_{3}^{n}-\left(1-\alpha_{3}\right) \frac{\Delta t}{\Delta y}\left(\varepsilon_{e}\right)_{3}^{n+1}\left(P_{O}^{n+1}-P_{S}^{n+1}\right)+ \\
& \alpha \rho_{f}\left(\varepsilon_{e} U_{o b j}^{y}\right)_{3}^{n+1} \\
\rho_{f}\left(\varepsilon_{e} u\right)_{4}^{n+1}= & \left(1-\alpha_{4}\right) \rho_{f}\left(\varepsilon_{e} u\right)_{4}^{n}+\left(1-\alpha_{4}\right) \Delta t\left(H_{y}\right)_{4}^{n}-\left(1-\alpha_{4}\right) \frac{\Delta t}{\Delta y}\left(\varepsilon_{e}\right)_{4}^{n+1}\left(P_{N}^{n+1}-P_{O}^{n+1}\right)+ \\
& \alpha \rho_{f}\left(\varepsilon_{e} U_{o b j}^{y}\right)_{4}^{n+1} \\
\rho_{f}\left(\varepsilon_{e} u\right)_{5}^{n+1}= & \left(1-\alpha_{1}\right) \rho_{f}\left(\varepsilon_{e} u\right)_{1}^{n}+\left(1-\alpha_{1}\right) \Delta t\left(H_{z}\right)_{1}^{n}-\left(1-\alpha_{1}\right) \frac{\Delta t}{\Delta z}\left(\varepsilon_{e}\right)_{5}^{n+1}\left(P_{O}^{n+1}-P_{B}^{n+1}\right)+ \\
& \alpha \rho_{f}\left(\varepsilon_{e} U_{o b j}^{z}\right)_{5}^{n+1} \\
& \left(1-\alpha_{6}\right) \rho_{f}\left(\varepsilon_{e} u\right)_{6}^{n}+\left(1-\alpha_{6}\right) \Delta t\left(H_{z}\right)_{6}^{n}-\left(1-\alpha_{6}\right) \frac{\Delta t}{\Delta z}\left(\varepsilon_{e}\right)_{6}^{n+1}\left(P_{F}^{n+1}-P_{O}^{n+1}\right)+ \\
& \alpha \rho_{f}\left(\varepsilon_{e} U_{o b j}^{z}\right)_{6}^{n+1} \\
\rho_{f}\left(\varepsilon_{e} u\right)_{6}^{n+1} & (30.6)
\end{aligned}
$$

In this method, the pressure at $(n+1)$ th time step can be computed as a sum of the predicted, $p^{*}$, and the corrected $p^{\prime}$ :

$$
p^{n+1}=p^{*}+p^{\prime}
$$

The predicted mass flow field, $\rho_{f} \varepsilon_{e} u$, is calculated by the predicted pressure field $p^{*}$ (the momentum equation at $p^{*}$ at 1 - 6 faces)

$$
\begin{aligned}
& \rho_{f}\left(\varepsilon_{e} u\right)_{1}^{*}=\left(1-\alpha_{1}\right) \rho_{f}\left(\varepsilon_{e} u\right)_{1}^{n}+\left(1-\alpha_{1}\right) \Delta t\left(H_{x}\right)_{1}^{n}-\left(1-\alpha_{1}\right) \frac{\Delta t}{\Delta x}\left(\varepsilon_{e}\right)_{1}^{n+1}\left(P_{O}^{*}-P_{w}^{*}\right)+ \\
& \alpha \rho_{f}\left(\varepsilon_{e} U_{o b j}^{x}\right)_{1}^{n+1} \\
& \rho_{f}\left(\varepsilon_{e} u\right)_{2}^{*}=\left(1-\alpha_{2}\right) \rho_{f}\left(\varepsilon_{e} u\right)_{2}^{n}+\left(1-\alpha_{2}\right) \Delta t\left(H_{x}\right)_{2}^{n}-\left(1-\alpha_{2}\right) \frac{\Delta t}{\Delta x}\left(\varepsilon_{e}\right)_{2}^{n+1}\left(P_{E}^{*}-P_{O}^{*}\right)+ \\
& \alpha \rho_{f}\left(\varepsilon_{e} U_{o b j}^{x}\right)_{2}^{n+1}
\end{aligned}
$$




$$
\begin{aligned}
& \rho_{f}\left(\varepsilon_{e} u\right)_{3}^{*}=\left(1-\alpha_{3}\right) \rho_{f}\left(\varepsilon_{e} u\right)_{3}^{n}+\left(1-\alpha_{3}\right) \Delta t\left(H_{y}\right)_{3}^{n}-\left(1-\alpha_{3}\right) \frac{\Delta t}{\Delta y}\left(\varepsilon_{e}\right)_{3}^{n+1}\left(P_{O}^{*}-P_{S}^{*}\right)+ \\
& \alpha \rho_{f}\left(\varepsilon_{e} U_{o b j}^{y}\right)_{3}^{n+1} \\
& \rho_{f}\left(\varepsilon_{e} u\right)_{4}^{*}=\left(1-\alpha_{4}\right) \rho_{f}\left(\varepsilon_{e} u\right)_{4}^{n}+\left(1-\alpha_{4}\right) \Delta t\left(H_{y}\right)_{4}^{n}-\left(1-\alpha_{4}\right) \frac{\Delta t}{\Delta y}\left(\varepsilon_{e}\right)_{4}^{n+1}\left(P_{N}^{*}-P_{O}^{*}\right)+ \\
& \alpha \rho_{f}\left(\varepsilon_{e} U_{o b j}^{y}\right)_{4}^{n+1} \\
& \rho_{f}\left(\varepsilon_{e} u\right)_{5}^{*}=\left(1-\alpha_{5}\right) \rho_{f}\left(\varepsilon_{e} u\right)_{5}^{n}+\left(1-\alpha_{5}\right) \Delta t\left(H_{z}\right)_{5}^{n}-\left(1-\alpha_{5}\right) \frac{\Delta t}{\Delta z}\left(\varepsilon_{e}\right)_{5}^{n+1}\left(P_{O}^{*}-P_{B}^{*}\right)+ \\
& \quad \alpha \rho_{f}\left(\varepsilon_{e} U_{o b j}^{z}\right)_{5}^{n+1} \\
& \rho_{f}\left(\varepsilon_{e} u\right)_{6}^{*}=\left(1-\alpha_{6}\right) \rho_{f}\left(\varepsilon_{e} u\right)_{6}^{n}+\left(1-\alpha_{6}\right) \Delta t\left(H_{z}\right)_{6}^{n}-\left(1-\alpha_{6}\right) \frac{\Delta t}{\Delta z}\left(\varepsilon_{e}\right)_{6}^{n+1}\left(P_{F}^{*}-P_{O}^{*}\right)+ \\
& \alpha \rho_{f}\left(\varepsilon_{e} U_{o b j}^{z}\right)_{6}^{n+1}
\end{aligned}
$$

The momentum equation at $\mathrm{n}+1$ as functions of momentum at * and p' (after 32-30 equations for all faces):

$$
\begin{aligned}
& \rho_{f}\left(\varepsilon_{e} u\right)_{1}^{n+1}=\rho_{f}\left(\varepsilon_{e} u\right)_{1}^{*}-\left(1-\alpha_{1}\right) \frac{\Delta t}{\Delta x}\left(\varepsilon_{e}\right)_{1}^{n+1}\left(P_{O}^{\prime}-P_{W}^{\prime}\right) \\
& \rho_{f}\left(\varepsilon_{e} u\right)_{2}^{n+1}=\rho_{f}\left(\varepsilon_{e} u\right)_{2}^{*}-\left(1-\alpha_{2}\right) \frac{\Delta t}{\Delta x}\left(\varepsilon_{e}\right)_{2}^{n+1}\left(P_{E}^{\prime}-P_{O}^{\prime}\right) \\
& \rho_{f}\left(\varepsilon_{e} u\right)_{3}^{n+1}=\rho_{f}\left(\varepsilon_{e} u\right)_{3}^{*}-\left(1-\alpha_{3}\right) \frac{\Delta t}{\Delta y}\left(\varepsilon_{e}\right)_{3}^{n+1}\left(P_{O}^{\prime}-P_{S}^{\prime}\right) \\
& \rho_{f}\left(\varepsilon_{e} u\right)_{4}^{n+1}=\rho_{f}\left(\varepsilon_{e} u\right)_{4}^{*}-\left(1-\alpha_{4}\right) \frac{\Delta t}{\Delta y}\left(\varepsilon_{e}\right)_{4}^{n+1}\left(P_{N}^{\prime}-P_{O}^{\prime}\right) \\
& \rho_{f}\left(\varepsilon_{e} u\right)_{5}^{n+1}=\rho_{f}\left(\varepsilon_{e} u\right)_{5}^{*}-\left(1-\alpha_{5}\right) \frac{\Delta t}{\Delta z}\left(\varepsilon_{e}\right)_{5}^{n+1}\left(P_{O}^{\prime}-P_{B}^{\prime}\right) \\
& \rho_{f}\left(\varepsilon_{e} u\right)_{6}^{n+1}=\rho_{f}\left(\varepsilon_{e} u\right)_{6}^{*}-\left(1-\alpha_{6}\right) \frac{\Delta t}{\Delta z}\left(\varepsilon_{e}\right)_{6}^{n+1}\left(P_{F}^{\prime}-P_{O}^{\prime}\right)
\end{aligned}
$$

For the cell $\mathrm{O}$, the pressure-correction equation can be obtained by substituting Equations A6 into Equation 1 and reorganizing the equation:

$$
a_{O} p_{O}^{\prime}+a_{W}^{\prime} p_{W}^{\prime}+a_{E}^{\prime} p_{E}^{\prime}+a_{S}^{\prime} p_{S}^{\prime}+a_{N}^{\prime} p_{N}^{\prime}+a_{B}^{\prime} p_{B}^{\prime}+a_{F}^{\prime} p_{F}^{\prime}=b
$$

where

$$
\begin{aligned}
& a_{W}^{\prime}=\left(1-\alpha_{1}\right)\left(\frac{\Delta t}{\Delta x}\right)^{2}\left(\varepsilon_{e}\right)_{1}^{n+1} \\
& a_{E}^{\prime}=\left(1-\alpha_{2}\right)\left(\frac{\Delta t}{\Delta x}\right)^{2}\left(\varepsilon_{e}\right)_{2}^{n+1} \\
& a_{S}^{\prime}=\left(1-\alpha_{3}\right)\left(\frac{\Delta t}{\Delta y}\right)^{2}\left(\varepsilon_{e}\right)_{3}^{n+1}
\end{aligned}
$$




$$
\begin{aligned}
& a_{N}^{\prime}=\left(1-\alpha_{4}\right)\left(\frac{\Delta t}{\Delta y}\right)^{2}\left(\varepsilon_{e}\right)_{4}^{n+1} \\
& a_{S}^{\prime}=\left(1-\alpha_{5}\right)\left(\frac{\Delta t}{\Delta z}\right)^{2}\left(\varepsilon_{e}\right)_{5}^{n+1} \\
& a_{N}^{\prime}=\left(1-\alpha_{6}\right)\left(\frac{\Delta t}{\Delta z}\right)^{2}\left(\varepsilon_{e}\right)_{6}^{n+1} \\
& a_{O}=-\left(a_{W}^{\prime}+a_{E}^{\prime}+a_{S}^{\prime}+a_{N}^{\prime}+a_{B}^{\prime}+a_{F}^{\prime}\right)
\end{aligned}
$$

and

$$
\begin{gathered}
b=\rho_{f}\left(\varepsilon_{e}\right)_{0}^{n+1}-\rho_{f}\left(\varepsilon_{e}\right)_{0}^{n}+\frac{\Delta t}{\Delta x}\left[\rho_{f}\left(\varepsilon_{e} u\right)_{2}^{*}-\rho_{f}\left(\varepsilon_{e} u\right)_{1}^{*}\right]+\frac{\Delta t}{\Delta y}\left[\rho_{f}\left(\varepsilon_{e} u\right)_{4}^{*}-\rho_{f}\left(\varepsilon_{e} u\right)_{3}^{*}\right]+ \\
\frac{\Delta t}{\Delta z}\left[\rho_{f}\left(\varepsilon_{e} u\right)_{6}^{*}-\rho_{f}\left(\varepsilon_{e} u\right)_{5}^{*}\right]
\end{gathered}
$$

\section{NUMERICAL SAMPLE PREPARATION METHOD AND SIMULATION PROCEDURES}

Prediction of sand production is a complex and difficult task because it covers multidisciplinary domains like geology, drilling, geophysics, geomechanics, fluid mechanics, reservoir engineering, petroleum engineering, production engineering, etc. Additionally, a hydrocarbon's field life has to be fully studied and take into account, where it has three major phases: Exploration, Development, and Production. All of each phase has specific objectives and a huge data for sand production problems can be collected. Capturing all the parameters influencing sand production classified by Veeken et al. (1991) and its mechanisms in the numerical models is difficult and the models have many limitations. Therefore, the aim of this study was not to simulate the real downhole conditions but to simplify them, reducing the number of parameters. To achieve this simplification and at the same time to mimic the real field conditions, for the well completion category one small perforation hole of the cased horizontal well was chosen as a simulation geometry (Figure 2).

All hydrocarbon reservoirs themselves are complicated geological heterogeneous bodies with rock properties (porosity, permeability, saturation, etc.) varying within the reservoir and they are not the homogeneous porous media that are often presented on papers and used in calculations (Dawe, 2004).

Since the aim of this research is dedicated to studying the behavior of sandstone material and its sanding mechanism, and the scale of the area under consideration is small (around one small perforation hole) one lithology in terms of cemented sandstone has been chosen and considered as a homogeneous media. For the fluid characterization part, a single liquid phase oil with low viscosity and density is considered.

For the rock characterization part, the previous research conducted by Rakhimzhanova et al. $(2018,2019 \mathrm{a})$ is used. Authors developed a simple 3D bond contact model for cemented sandstone material by modifying the previous existing JKR model for auto-adhesive silt size sand particles and reported the results obtained from 3D DEM simulations of triaxial compression tests of cemented sandstone of different density from loose to medium dense. The material properties of the cemented analogue samples from the Ustyurt-Buzachi Sedimentary 
Basin studied by Shabdirova et al. (2016) were reproduced for the numerical samples. Authors did not up-scale the spherical DEM particles sizes, i.e. they were equal to the real grain sizes, and these particles were connected together by interface energy. All simulations were performed in a periodic cell, which implies that the 'sample size' is infinite, there are no 'loading boundaries' and there is no finite size effect that may affect the results. Authors obtained the Mohr-Coulomb strength criterion parameters c'- inherent shear strength and $\varphi^{\prime}$ - friction angle for both systems were obtained and identified the best match with the experimental results strength parameters. The stress-strain curves obtained for the numerical samples showed good agreement with the experimental results of the cemented sandstone in terms of the in terms of the shear strength (Figure 3). Consequently, the microscopic response of experimental cemented sandstone material was examined by numerical results. It should be noted that the experimentally studied cemented analogue samples are not the core samples of overburden formations. The core samples are almost never available for comprehensive laboratory testing (Zoback, 2017).

Finally, the sand production simulations were divided into five stages: particle generation, pluvial deposition, compression, perforation penetration and sand production. This research extends the recent 3D DEM simulations of cone penetration tests in cemented sandstone performed by Rakhimzhanova et al. (2019b), where authors used the first four stages for cone penetration simulations (Subsections 3.1-3.4). Authors conducted series of of numerical CPT tests at different bond strength values and presented the result of numerical CPT tests in cemented sandstone which was found to be in good agreement with the Soil Behaviour Type (SBT) classification system from CPT data. In this study, these penetrated samples are used for the three-dimensional simulations of sand production tests.

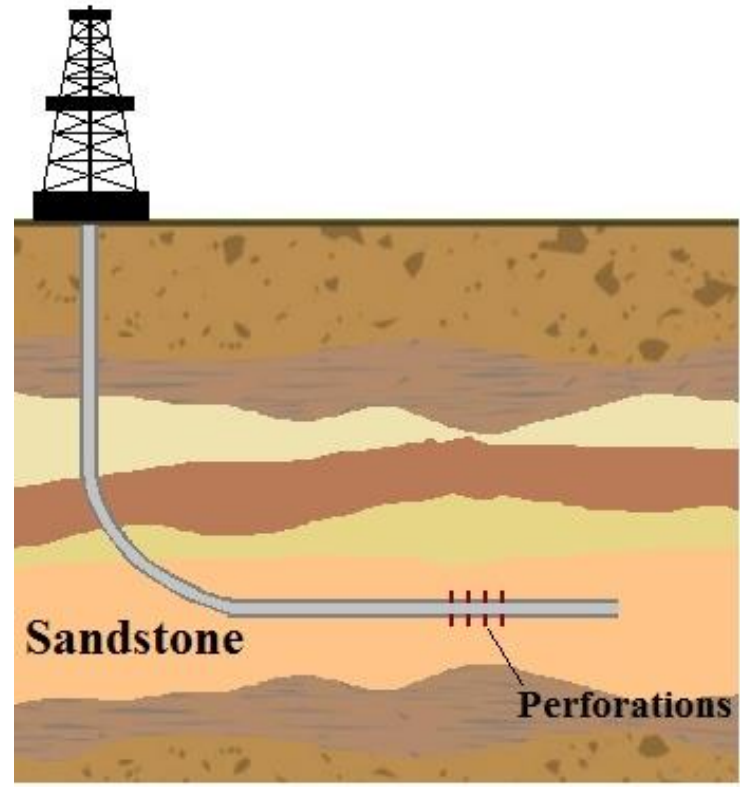

a) Horizontal well (field scale)

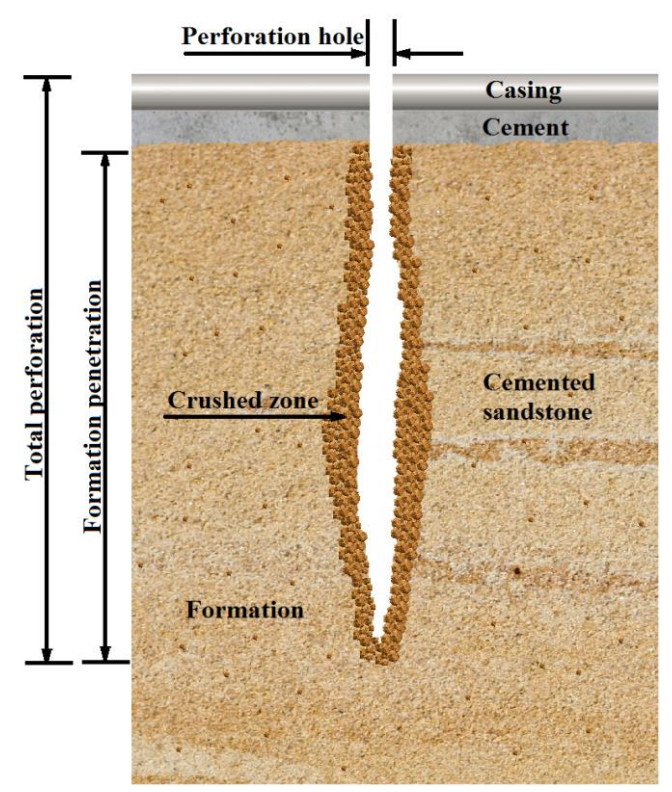

b) Perforation hole

Figure 2. Well completion of horizontal cased well 


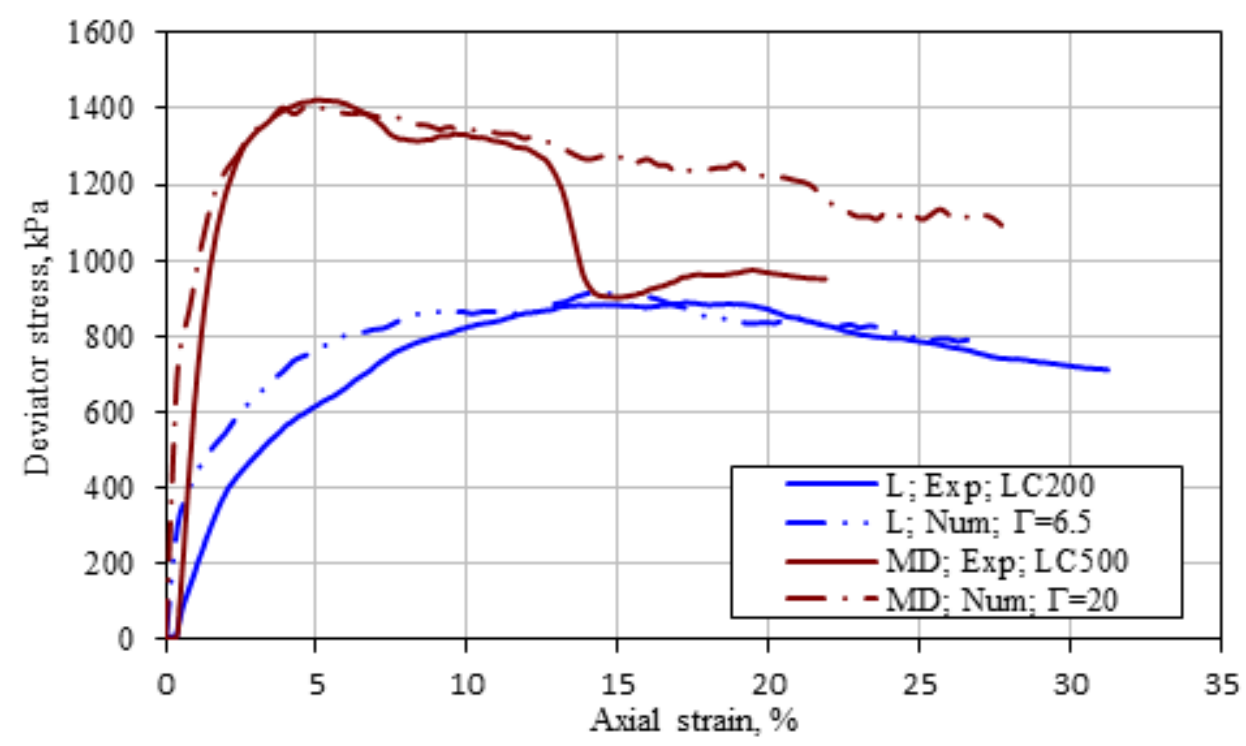

Figure 3. Comparison of numerical and experimental stress-strain curves for cemented sandstone samples (Rakhimzhanova et al., 2019)

\subsection{PARTICLE GENERATION}

The same eight different particle sizes from the particle size distribution (PSD) data of the cemented analogue samples from the Ustyurt-Buzachi Sedimentary Basin (Figure 4) measured by Qicpic dynamics image analyzer (Shabdirova et al. 2016) were selected. Within a thin rectangular parallelepiped workspace of dimension $8.4 \mathrm{~mm}$ in width, $21 \mathrm{~mm}$ in height and $1.4 \mathrm{~mm}$ in thickness 10000 particles were randomly generated (Figure $5 \mathrm{a}$ ): $0.15 \mathrm{~mm}$ (1179), 0.18 $\mathrm{mm}$ (1750), $0.2 \mathrm{~mm}$ (1505), $0.22 \mathrm{~mm}$ (1558), $0.25 \mathrm{~mm}$ (1973), $0.275 \mathrm{~mm}$ (1119), $0.3 \mathrm{~mm}(610)$, $0.355 \mathrm{~mm}$ (306). The workspace was divided into small 720 DEM boxes (box dimension of $0.0007 \mathrm{~mm}$ ): 12 in width, 30 in height and 2 in thickness. The following material properties were used for all particles: Young's modulus E=70 GPa, Poisson ratio $v=0.3$ and experimental particle density $\rho=2605 \mathrm{~kg} / \mathrm{m}^{3}$.

\subsection{PLUVIAL DEPOSITION}

To form the initial homogeneous bed a vertical gravity field was applied to the system, where all particles were pluvially deposited (Figure 5b). One finite wall was created at the bottom of workspace in order to avoid/prevent the periodic boundary condition at this side. The following material properties of iron were used for all walls: Young's modulus $\mathrm{E}=210 \mathrm{GPa}$, Poisson ratio $v=0.29$ and experimental particle density $\rho=7900 \mathrm{~kg} / \mathrm{m}^{3}$.

\subsection{COMPRESSION}

Three top finite walls were created at the top of the deposited specimen and moved down with a wall velocity of $0.1 \mathrm{~m} / \mathrm{s}$ in order to vertically compress the sample; these three finite walls imitate the well casing (Figure 5c). When a vertical stress level ( $S_{\mathrm{v}}$ overburden pressure) reached $S_{\mathrm{v}}=500 \mathrm{kPa}$, the interparticle friction and wall friction coefficients were set to $\mu_{p}=0.3$ and $\mu_{w}$ $=0.3$, respectively; the identified bond strength values for cemented sandstone by 
Rakhimzhanova et al. (2019) $\Gamma=20 \mathrm{~J} / \mathrm{m}^{2}$ was set in order to make a cementation of medium dense specimen (Figure 4), any bond breakage event was started to count from this moment. When the overburden pressure reached $S_{\mathrm{v}}=1 \mathrm{MPa}$, the top three wall velocities were reset to 0 .

The Overburden pressure is defined as

$$
S_{v}=\int_{0}^{z} \rho(z) g \mathrm{dz} \approx \rho_{r} g z
$$

where, $\rho_{r}$ is rock density, $g$ is gravitational acceleration, and $z$ is depth of interest. Using the Eq.43, the depth of interest was found and it is equal to $39.1 \mathrm{~m}$.

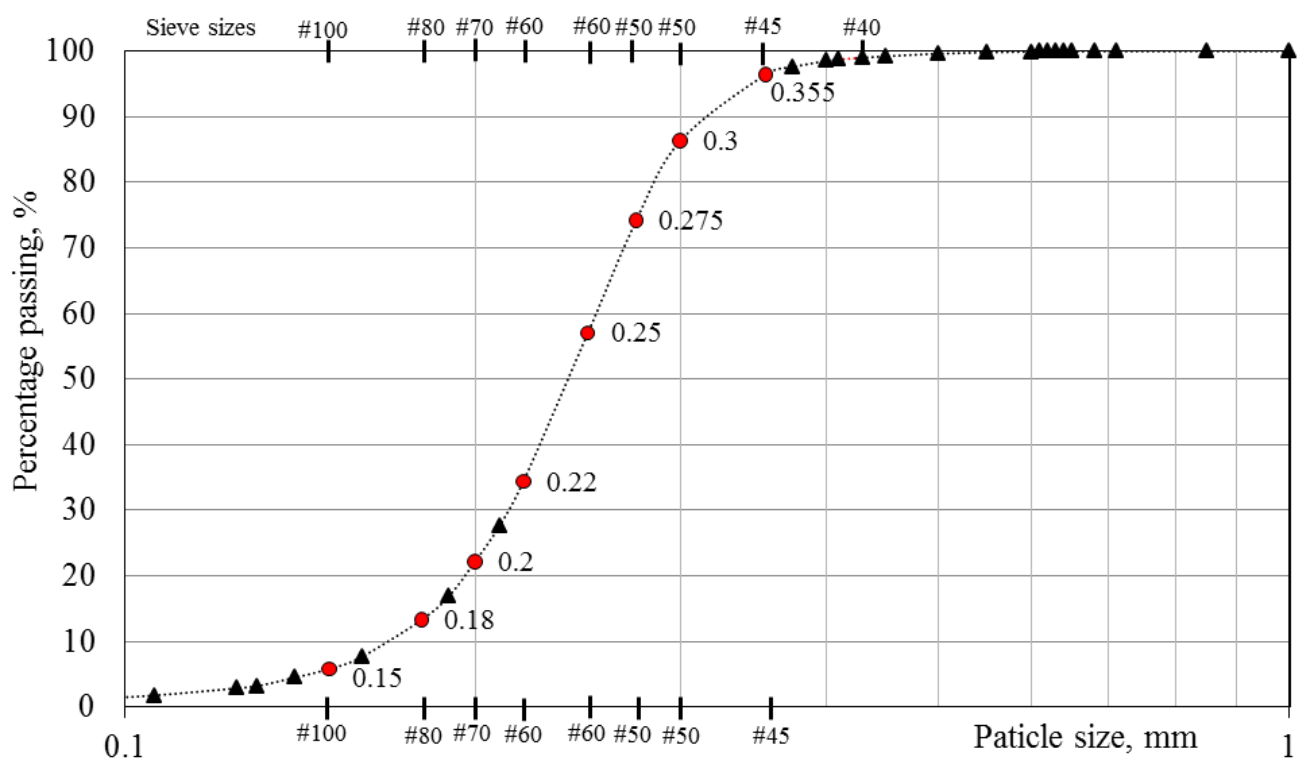

Figure 4. Grain size distribution (Rakhimzhanova et al., 2019b)

\subsection{PERFORATION PENETRATION}

After the compression of DEM cemented sandstone, a standard cone penetrometer was first created above the bed and then pushed down at a high constant rate of $0.1 \mathrm{~m} / \mathrm{s}$ in order to avoid computational cost. The penetrometer had a "radius" $R$ of $0.8 \mathrm{~mm}$ and an apex angle of $60^{\circ}$. It was defined as 2 rigid frictional walls inclined to $\mathrm{X}$-axis at $60^{\circ}$ to simulate the cone penetrometer and two rigid vertical frictional walls to simulate the penetrometer sleeve (Figure $5 \mathrm{~d})$. The cone penetrometer was removed from the penetrated specimen once the cone tip had reached the depth $\mathrm{y} / \mathrm{R}=3.5$. 


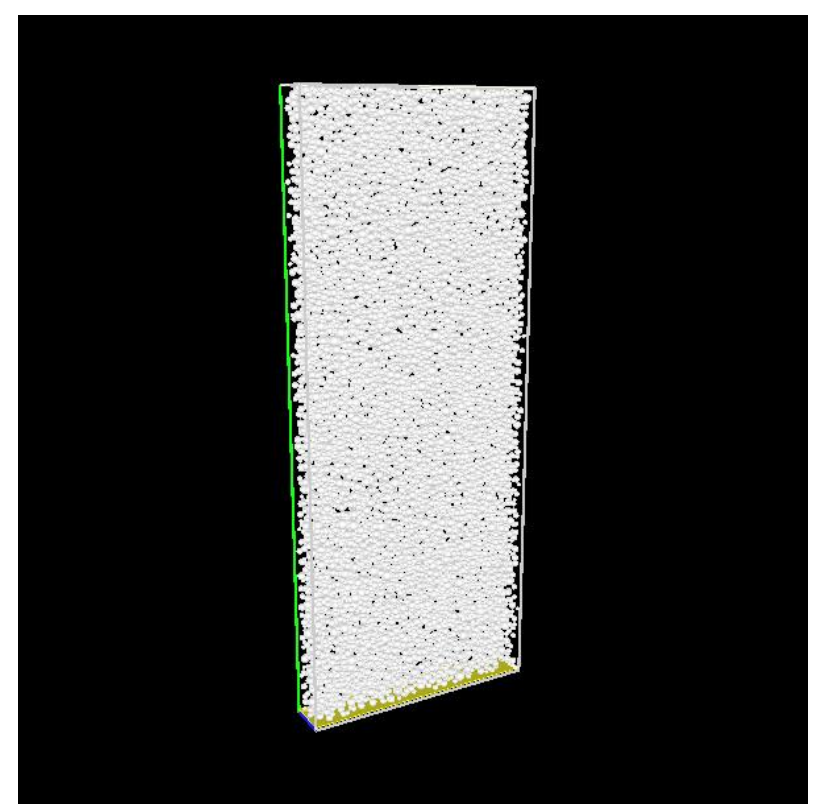

a) Particle generation

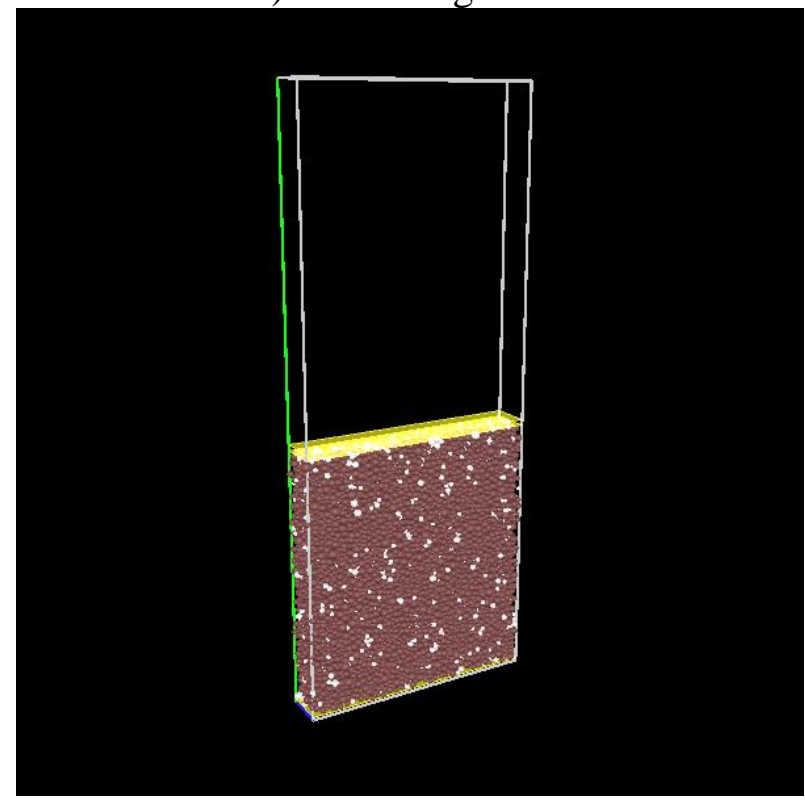

c) Compression

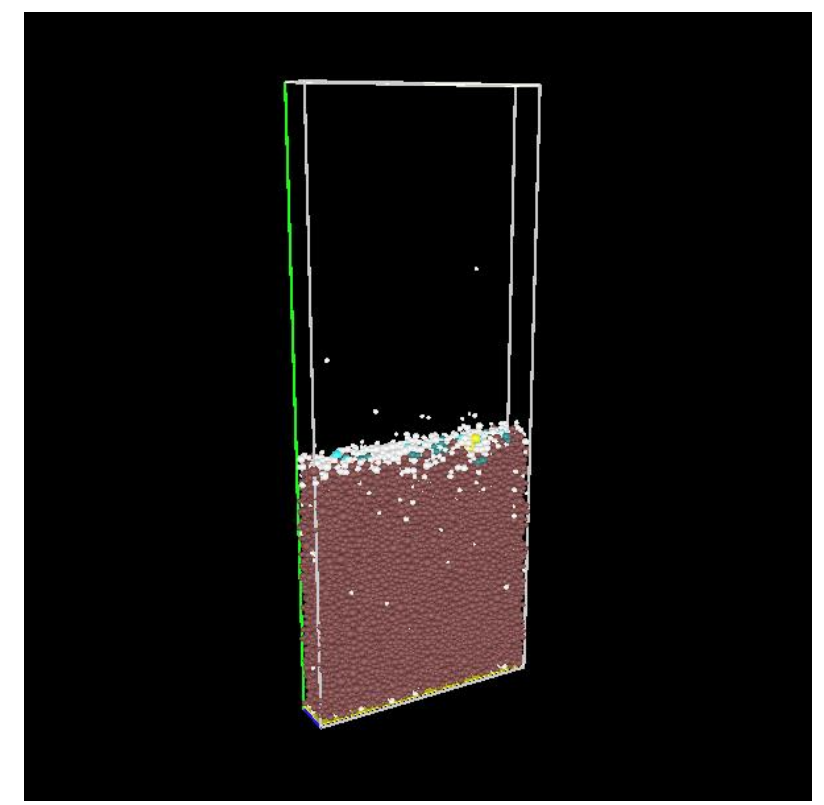

b) Pluvial deposition

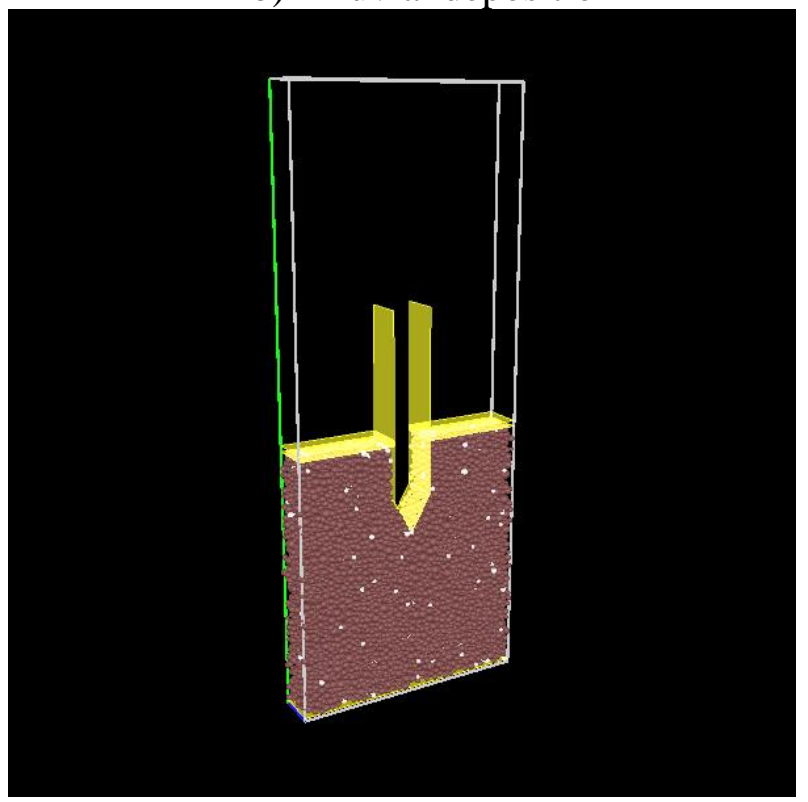

d) Cone perforation

Figure 5. Perforation penetration simulation stages (Rakhimzhanova et al., 2019b)

\subsection{SAND PRODUCTION}

The following fluid properties were used for sand production simulation: oil density $\rho_{\text {oil }}$ $=850 \mathrm{~kg} / \mathrm{m}^{3}$ and shear viscosity $\eta_{\text {oil }}=0.52 \cdot 10^{-3} \mathrm{~Pa}^{-1} \mathrm{~s}^{-1}$ (Agada et al., 2014). The following fluid boundary conditions were set for numerical samples: periodic boundary for left and right sides, impermeable free lip for back and front sides, and prescribed pressure for bottom and top sides.

Top solid walls represent the perforated casing of the horizontal well, where the two lowest finite horizontal walls (at the end of compression) are not necessarily located to coincide 
with any fluid cell boundary. Consequently, they treated as immersed boundaries during the sand production simulation with the no-slip and impermeable conditions. The upper two finite horizontal walls and two finite vertical walls that connected these upper and lower finite horizontal walls are coincide with fluid cell boundary.

The different pressures were specified for the bottom and top sides of the specimen to mimic the real field pressure drawdown (the difference between the reservoir pressure $P_{r}$ and the flowing wellbore pressure $P_{w}$ ) that drives fluids from the reservoir into the wellbore.

The reservoir pressure assumed to be equal to the pore pressure at depth, where the pore pressure is defined as a scalar hydraulic potential acting within an interconnected pore space at depth:

$$
P_{p} \approx P_{r}=\int_{0}^{z} \rho_{\text {oil }}(z) g \mathrm{dz} \approx \rho_{\text {oil }} g z_{\text {oil }}
$$

where, $z_{\text {oil }}=\mathrm{z}=39.1 \mathrm{~m}$ and it is a depth of interest (depth, where oil locates). The reservoir pressure at $39.1 \mathrm{~m}$ was calculated using Eq. 44 and it is equal to $P_{r}=326296 \mathrm{~Pa}$ (pressure at the bottom side of specimen). The wellbore pressure assumed to be equal $P_{w}=101325 \mathrm{~Pa}$ (pressure at the top side of specimen).

\section{NUMERICAL RESULTS}

Figure 6 shows the sand production at $0.0295 \mathrm{sec}$ for bond strength $\Gamma=20 \mathrm{~J} / \mathrm{m}^{2}$, and at this state the quantity of produced sand grains is 266 (Figure 7a) and the mass is $4.33 \mathrm{mg}$ (Figure 7b).

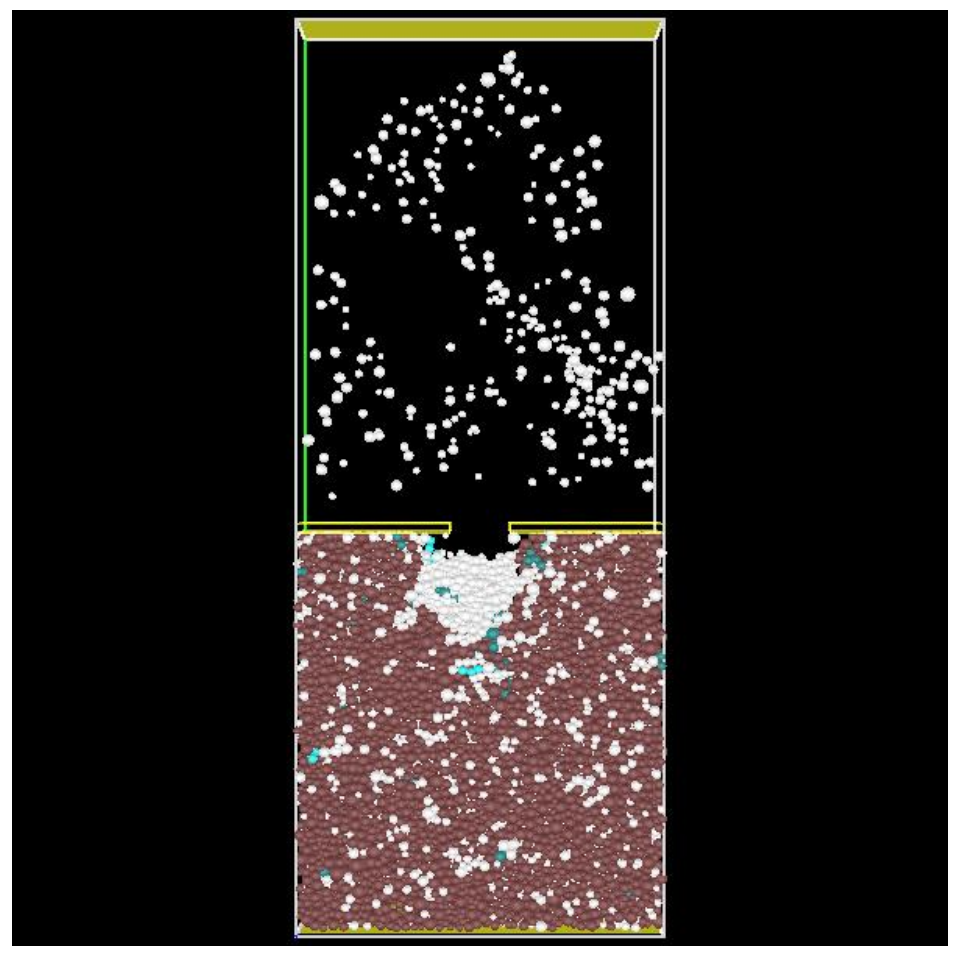

Figure 6. Sand production 


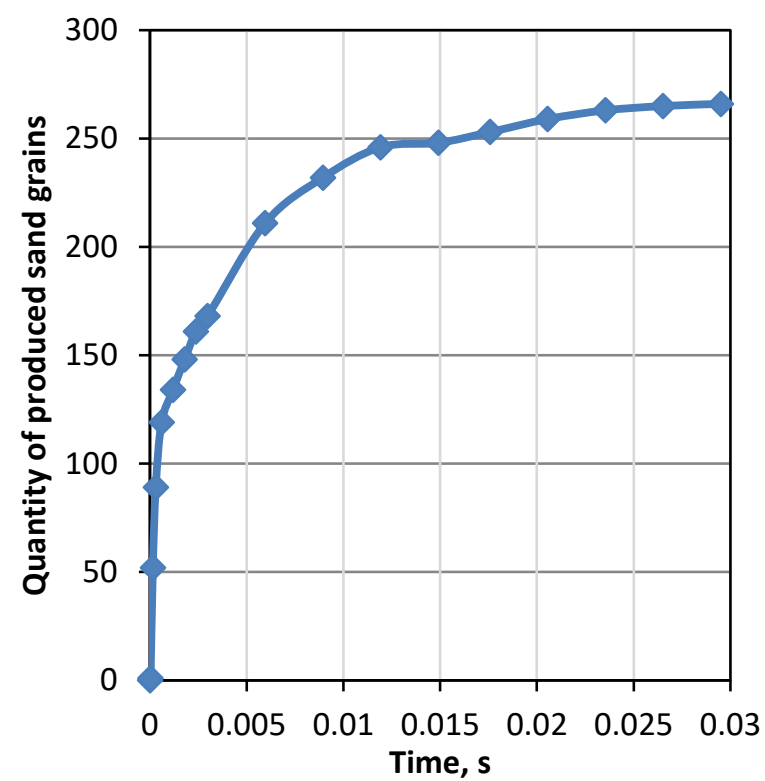

a) Quantity

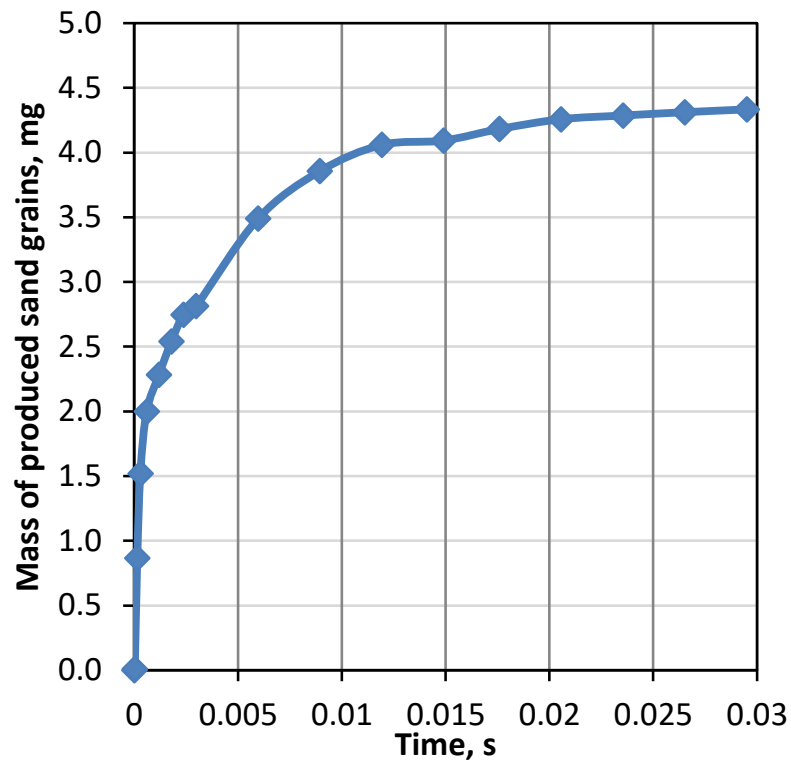

b) Mass

Figure 7. Data of produced sand

The figure 8 shows the produced sand particle positions at initial $(0 \mathrm{sec})$ and current $(0.0295 \mathrm{sec})$ states, where the data of initial positions (data points located below the IBM walls, near the perforation hole) have been taken just after the perforation stage. It has shown that the all produced sand particles (data points located above the IBM walls) came from perforation damage zone (skin), and at the current state the migration of fine particles from remote zone through channels had not detected. 


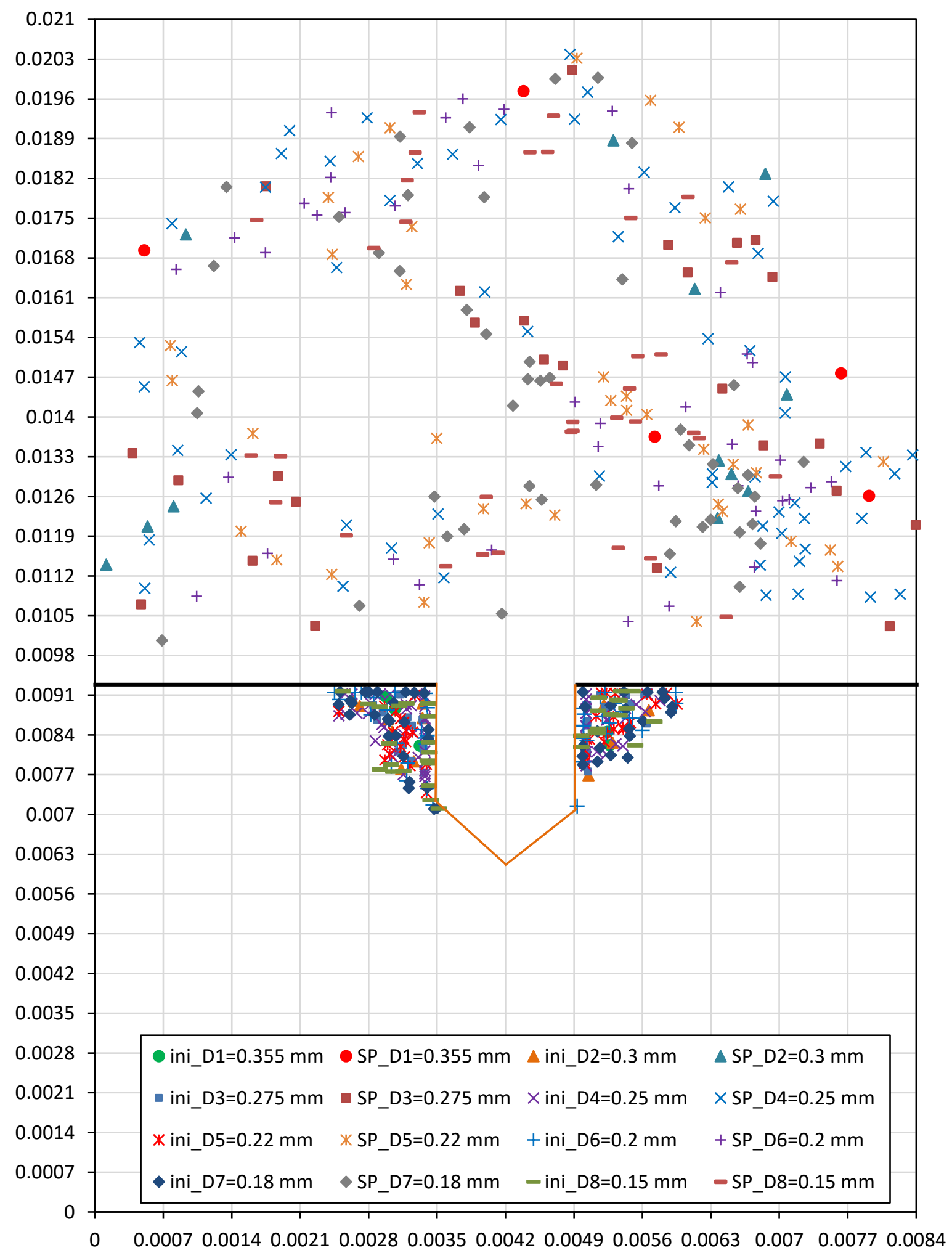

Figure 8. Erosion near the perforation hole 
At the very beginning of sand production simulation $(0.00003 \mathrm{sec})$ a sand arch was captured (Figure 9).

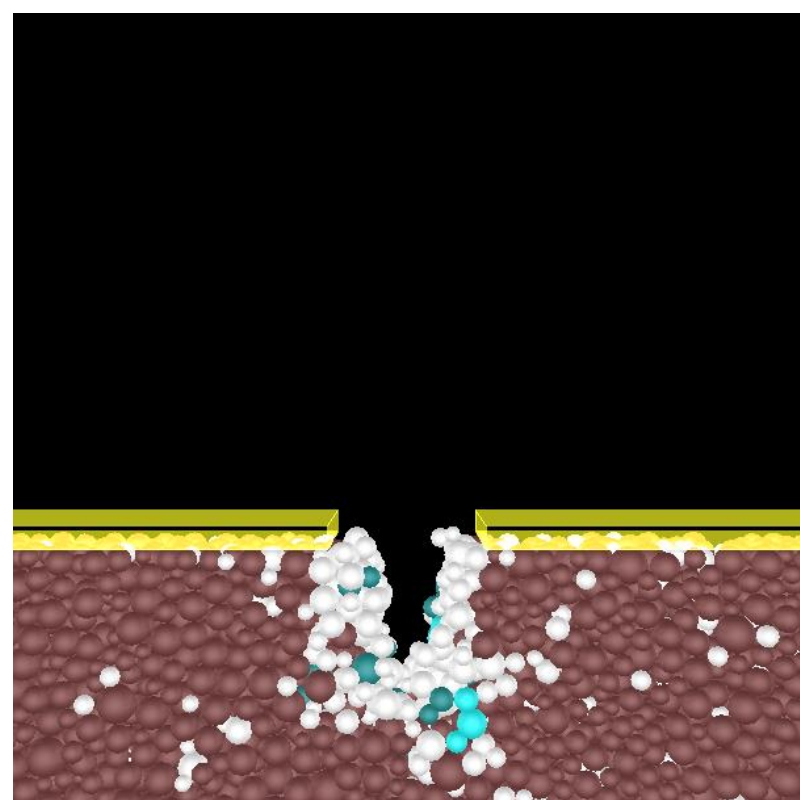

Figure 9. Sand arch at $0.00003 \mathrm{sec}$ (the different colours indicate the cluster size: white particles have 1 particle in one cluster, light cyan 2 and dark cyan 3 )

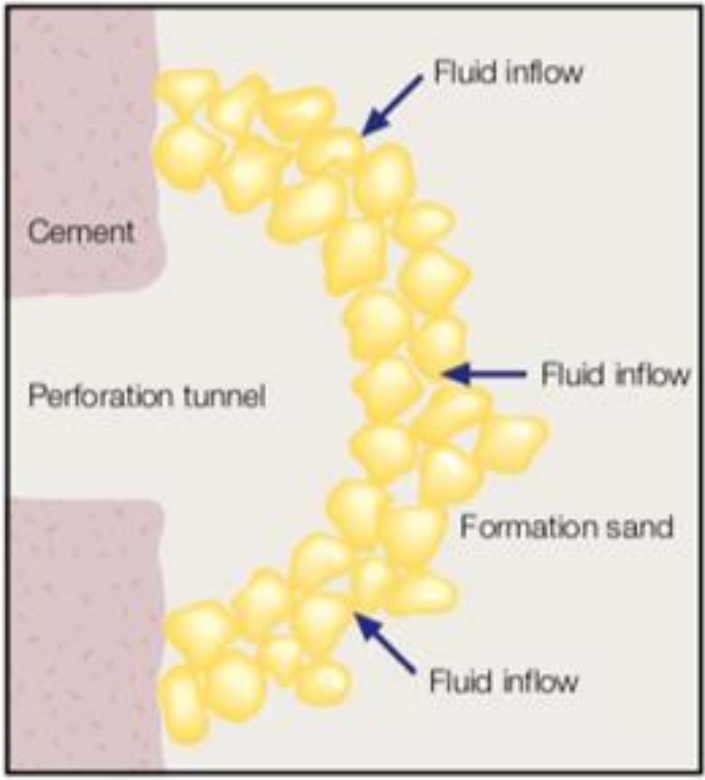

Figure 10. Illustration of sand arch (Carlson et al., 1992)

Carlson et al (1992) stated that sanding onset is caused by the fluid flow initiation and the drag forces associated with it. The sand grains detach from the matrix and transported to perforation hole. The effect is directly proportional to the fluid viscosity and its velocity and with high-pressure differentials during drawdown, which results in stable arch around the entrance to be formed around a perforation cavity (Figure 10). The stability of the arch depends on the constant flow velocity and drawdown. After the change in the flow velocity and the drawdown, the arch collapses and a new one is generated.

The figure 11 shows the perforation damage zone in term of compressive (orange) and tensile (mild green) contact forces at $0.0295 \mathrm{sec}$ and it demonstrates that the size of arch becomes larger.

Figure 12 shoes the fluid velocity vectors when the IBM method is used. The sample configuration for sand production problem is utilized, where the cemented sandstone material has removed in order to see the fluid behaviour near the IBM walls and perforation hole. 


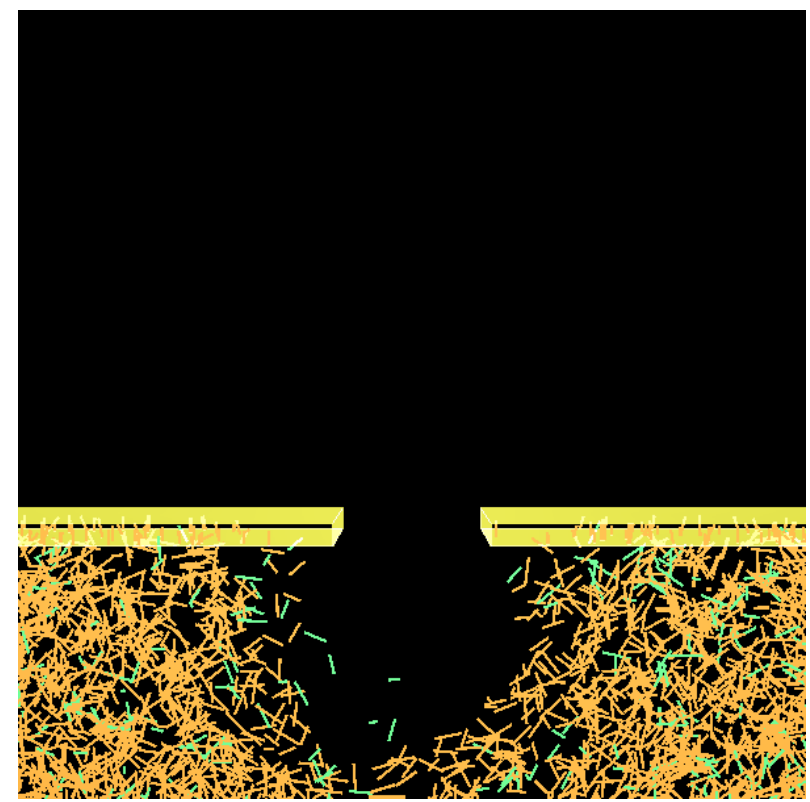

Figure 11. The perforation damage zone at $0.0295 \mathrm{sec}$

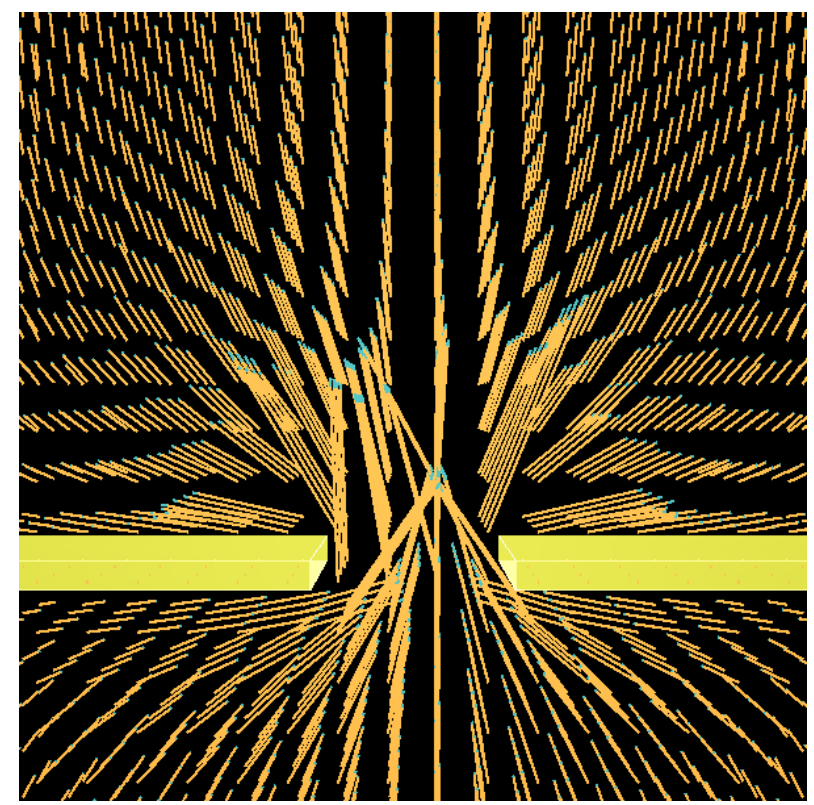

Figure 12. Fluid flow near the IBM walls

\section{CONCLUSION}

This preprint paper is the extension of the work conducted by Rakhimzhanova et al. (2019b), where authors performed 3D DEM simulations of cone penetration in cemented sandstone material with the realistic grain sizes. One of the previously numerically penetrated sandstone sample with bond strength $\Gamma=20 \mathrm{~J} / \mathrm{m}^{2}$ is used to perform the numerical simulation of sand production in horizontal cased wells using 3D CFD-DEM-IBM approach, where the IBM method was optimized for sample geometry. Sanding mechanism due to the pressure drawdown was examined, where the fluid flows (oil) have been driven due to the difference between the base and top boundary pressures of the workspace and lifted the eroded sand particles. The results show that all produced sand particles came from the perforation damage zone; and the migration of fine particles had not detected from remote zone through channels. Sand arch was numerically captured, and the perforation cavity changed the size and becomes larger due to the sand arch collapse; the mass and amount of produced sand particles have been calculated.

The aim of this paper is to demonstrate the capability of the numerical approach to study the sanding mechanism at macro and micro scales. This study will be continued; number of improved numerical simulations will be conducted and full results well be published in the near future.

\section{ACKNOWLEDGMENTS}

This research was supported by the Nazarbayev University Faculty Development Competitive Research Grant No 110119FD4502 and by the EU Project GEO-RAMP (H2020-MSCA-RISE2014 GA 645665). The authors gratefully acknowledge Prof. Stefano Utili (Newcastle University) and Dr. Helen Cheng (University College London) for their help during the first 
author's visits to the UK; Prof. Yu Guo (Zhejiang University) for his help and suggestions in the IBM part; and Sand production research group at Nazarbayev Univesity.

\section{REFERENCES}

Agada S, Chen F, Geiger S, Toigulova G, Agar S, Shekhar R, Benson G, Hehmeyer O, Amour F, Mutti M, Christ N. Numerical simulation of fluid-flow processes in a 3D high-resolution carbonate reservoir analogue. 2014:125-142

Anderson TB, Jackson R. Fluid mechanical description of fluidized beds. Equations of motion. Industrial \& Engineering Chemistry Fundamentals. 1967 Nov;6(4):527-39.

Bird RB, Stewart WE, Lightfoot EN. Transport phenomena john wiley \& sons. New York. $1960 ; 413$.

Bjorlykke K. Petroleum geoscience: From sedimentary environments to rock physics. Springer Science \& Business Media; 2010 Sep 16.

Carlson J, Gurley D, King G, Price-Smith C, Waters F. Sand control: Why and how?. Oilfield Review. 1992 Oct 1;4(4):41-53.

Cheung LY. Micromechanics of sand production in oil wells (Doctoral dissertation, Imperial College London, 2010).

Climent Pera N. A coupled CFD-DEM model for sand production in oil wells (Doctoral dissertation, Universitat Politècnica de Catalunya BarcelonaTech, 2016).

Cui Y, Nouri A, Chan D, Rahmati E. A new approach to DEM simulation of sand production. Journal of Petroleum Science and Engineering. 2016 Nov;147:56-67.

Cundall PA, Strack ODL. A discrete numerical model for granular assemblies. Géotechnique. 1979 Mar;29(1):47-65.

Dawe RA. Miscible Displacement in heterogeneous porous Media. In Proceedings of the sixth Caribbean Congress of fluid dynamics Trinidad, West Indies January 2004 (pp. 21-23).

Di Felice R. The voidage function for fluid-particle interaction systems. International journal of multiphase flow. 1994 Feb 1;20(1):153-9.

Guo Y, Wu C-Y, Thornton C. Modeling gas-particle two-phase flows with complex and moving boundaries using DEM-CFD with an immersed boundary method. AIChE Journal. 2012 Aug 20;59(4):1075-87.

Hertz H. Ueber die Berührung fester elastischer Körper. Journal für die reine und angewandte Mathematik (Crelles Journal). 1882 Jan 1;1882(92):156-71. 
Jensen RP, Preece DS. Modeling sand production with Darcy-flow coupled with discrete elements. Sandia National Labs., Albuquerque, NM (US); Sandia National Labs., Livermore, CA (US); 2000 Aug 10.

Johnson KL, Kendall K, Roberts AD. Surface energy and the contact of elastic solids. Proceedings of the Royal Society of London A Mathematical and Physical Sciences. 1971 Sep 8;324(1558):301-13.

Johnson KL. Adhesion at the contact of solids. In: Koiter, W.T. (ed.) Theoretical and Applied Mechanics. Proceedings of the 4th IUTAM Congress; 1976:133-143.

Kafui KD, Thornton C, Adams MJ. Discrete particle-continuum fluid modelling of gas-solid fluidised beds. Chemical Engineering Science. 2002 Jul;57(13):2395-410.

Kajishima T, Takiguchi S, Hamasaki H, Miyake Y. Turbulence structure of particle-laden flow in a vertical plane channel due to vortex shedding. JSME International Journal Series B Fluids and Thermal Engineering. 2001;44(4):526-35.

Kuipers JAM, van Duin KJ, van Beckum FPH, van Swaaij WPM. Computer simulation of the hydrodynamics of a two-dimensional gas-fluidized bed. Computers \& Chemical Engineering. 1993 Aug;17(8):839-58.

Li L, Holt RM. Particle Scale Reservoir Mechanics. Oil \& Gas Science and Technology. 2002 Sep;57(5):525-38.

Li L, Papamichos E, Cerasi P. Investigation of sand production mechanisms using DEM with fluid flow. Multiphysics Coupling and Long Term Behaviour in Rock Mechanics. 2006 May;1:241-7.

Mindlin RD. Compliance of elastic bodies in contact. J. Appl. Mech., ASME. 1949;16:259-68.

O'Connor RM, Torczynski JR, Preece DS, Klosek JT, Williams JR. Discrete element modeling of sand production. International Journal of Rock Mechanics and Mining Sciences. 1997 Apr;34(3-4):231.e1-231.e15.

Patankar SV. Numerical heat transfer and fluid flow, Hemisphere Publ. Corp., New York. 1980;58.

Peskin CS. Flow patterns around heart valves. InProceedings of the Third International Conference on Numerical Methods in Fluid Mechanics 1973 (pp. 214-221). Springer, Berlin, Heidelberg.

Rahmati H, Jafarpour M, Azadbakht S, Nouri A, Vaziri H, Chan D, et al. Review of Sand Production Prediction Models. Journal of Petroleum Engineering. 2013;2013.

Rakhimzhanova A, Thornton C, Amanbek Y, Zhao Y. Numerical simulations of cone penetration tests in cemented sandstone. $2019 \mathrm{~b}$. 
Rakhimzhanova AK, Khamitov FA, Minh NH, Thornton C. 3D DEM simulations of triaxial compression tests of cemented sandstone. In Proceedings of IS Atlanta 2018 symposium on geomechanics from micro to macro in research and practice, Atlanta, USA 2018.

Rakhimzhanova AK, Thornton C, Minh NH, Fok SC, Zhao Y. Numerical simulations of triaxial compression tests of cemented sandstone. Computers and Geotechnics. 2019a;113:103068.

Shabdirova AD, Bissekenova Z, Minh NH, Kim JR. Sample preparation method of clay-rich sandstone analogue of sandstone reservoirs in Kazakhstan. Proceedings of the 50th US Rock Mechanics / Geomechanics Symposium 2016;2:904-910. Rock Mechanics Association (ARMA).

Tsuji Y, Kawaguchi T, Tanaka T. Discrete particle simulation of two-dimensional fluidized bed. Powder Technology. 1993 Oct;77(1):79-87.

Veeken CA, Davies DR, Kenter CJ, Kooijman AP. Sand production prediction review: developing an integrated approach. In SPE annual technical conference and exhibition 1991 Jan 1. Society of Petroleum Engineers.

Yuki Y, Takeuchi S, Kajishima T. Efficient immersed boundary method for strong interaction problem of arbitrary shape object with the self-induced flow. Journal of Fluid Science and Technology. 2007;2(1):1-1.

Zhou ZY, Yu AB, Choi SK. Numerical simulation of the liquid-induced erosion in a weakly bonded sand assembly. Powder Technology. 2011 Aug;211(2-3):237-49.

Zoback MD. Reservoir geomechanics: Earth stress and rock mechanics applied to exploration. Production and wellbore stability. 2007:449. 